\title{
El absurdo de la interpretación económica del "Hecho Generador". Derecho y su autonomía. La paradoja de la interdisciplinariedad ${ }^{(*)}\left(*^{* *}\right)$
}

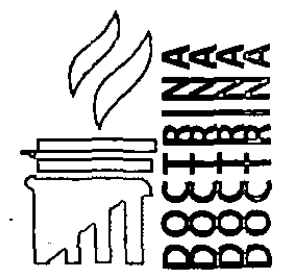

\section{Paulo De Barros Carvalho}

Profesor Titular de la Pontificia Universidad Católica de Sao Paulo y de la Universidad de Sao Paulo.

SUMARIO:

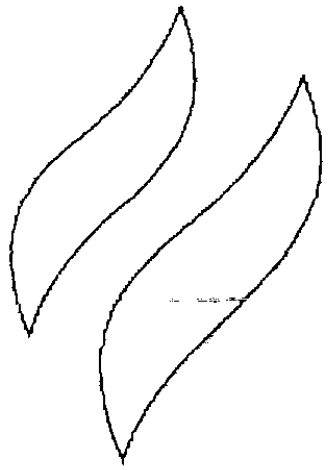

I. Introducción.

II. El contenido prescriptivo del lenguaje del Derecho Positivo.

III. Observaciones sobre las unidades que componen el sistema del Derecho Positivo.

IV. Disciplinariedad y autonomía del Derecho.

V. Interpretación de los hechos: delimitación del contenido de "hecho puro", "hecho contable" y" hecho juridico".

VI. La concepción del Derecho como sistema autopoiético.

VII. La imposibilidad de traducciones perfectas entre los idiomas de la misma familia y el diálogo que entre ellos se establece según la concepción de Vilém Flusser.

VIII. Conclusión. 


\section{INTRODUCCIÓN}

El objetivo del presente texto es poner en evidencia, aunque de forma breve, la autonomía del derecho con relación a otras materias que están próximas, afirmando premisas en el carácter sintácticamente homogéneo que el derecho positivo presenta como sistema empírico, formado por unidades atómicas -las normas jurídicas- expresadas verbalmente por medio de proposiciones prescriptivas. Descansa, por lo tanto, en dos premisas: a) que el derecho legislado, como clase lingüística, se estructura en forma de sistema autónomo; $y b$ ) que los elementos de ese conjunto son normas jurídicas (aqui utilizadas en el sentido estricto), expresadas mediante proposiciones hipotéticocondicionales. A partir de ahí, se establece la tesis según la cual uno de los aspectos del referido sistema es, justamente, el de ser homogéneo, en términos sintácticos, constituyente de una realidad propiamente suya.

Es prescindible advertir que cada una de las palabras utilizadas en esta estricta comunicación sirve de tema para amplias e interminables confrontaciones académicas. Las construcciones jurídico-filosóficas vienen demostrando, iterativamente, que los más simples vocablos de la terminología que empleamos ofrecen un material precioso para desacuerdos fundamentales, incluso dentro de una única corriente de pensamiento. No obstante, para hacer posible el aislamiento temático de la propuesta, suspendo, momentáneamente, la atención sobre los problemas que tal vez puedan suscitarse, para orientarla al examen tópico de ciertos puntos, a propósito de los que aduciré algunas consideraciones que me parecen oportunas.

\section{EL CONTENIDO PRESCRIPTIVO DEL LENGUAJE DEL DERECHO POSITIVO}

Doy por asentado que el estudio del derecho positivo, como estrato del lenguaje, no implica una toma de posición reductora del fenómeno jurídico, sino que supone admitir que el conjun- to de símbolos utilizados para la comunicación entre los seres humanos, en el contexto social, adquiere una de las formas particulares de interacción simbólica, compatible con la función reguladora del derecho, en la alteridad substancial que le es inmanente. Y ese modo específico es el del lenguaje prescriptivo.

De hecho, tanto el discurso informativo, propio para las transmisiones cognoscitivas; como el expresivo de situaciones subjetivas, como las emociones; e incluso aquel peculiar de la formulación de preguntas, que refleja la perplejidad del sujeto ante realidades que desconoce; esas tres funciones del lenguaje no se ajustan al fin primordial del derecho, en su misión reguladora de relaciones intersubjetivas. Para realizar tal finalidad ordenadora, el instrumento adecuado es el lenguaje prescriptivo de situaciones, es decir, "del lenguaje cuya finalidad es alterar la circunstancia y cuyo destinatario es el hombre y su conducta en el universo social. Se altera el mundo físico mediante el trabajo y la tecnología, que lo potencia en resultados. Y se altera el mundo social mediante el lenguaje de las normas, una clase de la que es el lenguaje de las normas del Derecho", como se extrae de la vigorosa lección de Lourival Vilanova.'

Pues bien, ese carácter prescriptivo, vectorial, penetra intensamente en toda la textura del sistema del derecho legislado que se vierte sobre la facticidad social, identificando a personas, situaciones y cosas, exactamente para asociarles la regulación de las conductas interhumanas.

\section{OBSERVACIONES SOBRE LAS UNIDADES QUE COMPONEN EL SISTEMA DEL DERECHO POSITIVO}

Cuando menciono el derecho legislado, en su condición de sistema, es para afrontarlo no como sistema lógico, dotado de consistencia, exento de contradicciones, tal cual el modelo del sistema de las ciencias, sino como conjunto de proposiciones lingüísticas que se dirigen a una cierta y determinada región material -la

1 VILANOVA, Lourival, As estruturas Lógicas e o Sistema do Direito Positivo, Ed. RT, São Paulo, 1977, pp. 3 y 4. 
región material de las conductas interpesonales-. El discurso al que me refiero, aunque abriga proposiciones contradictorias y lagunas, incluso así, viene cargado de una porción de racionalidad que juzgo suficiente para otorgarle carácter de sistema, no lógico, sino empírico, precisamente por el compromiso que mantiene con el tejido social, por él ordenado de manera prescriptiva.

Ahora bien, guardando la forma de sistema, las unidades que componen el derecho positivo son las normas jurídicas, juicios hipotéticocondicionales, en la que se enlaza al antecedente, o descriptor, un consecuente, o prescriptor, todo por intermedio de la copula deóntica -el "deber ser"-, en su configuración neutra, esto es, sin modalización. Estas entidades lógicas (los juicios hipotéticos) ganan expresión verbal en forma de proposiciones -proposición hipótesis y proposición tesis- unidas por el conector peculiar al dominio del normativo-social, al que ya me he referido.

Es bueno recordar que, en los fenómenos de incidencia normativa, componentes de una nueva realidad jurídica, hay dos normas que deben ajustarse, respectivamente, a la norma general y abstracta y la norma individual y concreta. En el plano de la formulación normativa, todo se inicia con la construcción de una clase o conjunto que enumera los individuos que la componen, $o$ indica las notas o nota que el individuo precisa tener para pertenecer a la clase o conjunto. La primera es la forma tabular; la segunda, la forma de construcción. La modalidad en que, casi siempre, se manifiesta la proposición normativa general y abstracta no es la forma tabular, sino la forma de construcción. En ella se establecen las notas (connotación) que los sujetos o las acciones deben tener para pertenecer al conjunto. La relación de pertenencia es determinada connotacionalmente. Este el modo más frecuente en el derecho positivo. Sería interminable formar clases por enumeración de los individuos o acciones, ya que lo real es irrepetible y la experiencia es infinita e inagotable.
Cada enunciado que se forme, que contenga los caracteres seleccionados en la composición típica de la hipótesis, se subsumirá en aquel conjunto que, de esta forma, podrá recibir número infinito de ocurrencias fácticas. Es bueno tener presente que la formación de esos segmentos lingüísticos con sentido completo presupone un proceso selectivo, con la elección de los rasgos juzgados más relevantes para la identificación del objeto de la experiencia, que refleja, no lo real, sino un punto de vista sobre lo real, como destaca Samira Chalhub. ${ }^{2}$ Al fin de cuentas, un concepto demarcado es siempre selector de propiedades, ya que los infinitos aspectos de lo real pasan por el juicio de valor emitido por el autor del acto de habla, en este caso, el legislador.

A esta altura, ya podemos decir que el enunciado factual es protocolario, que sorprende una alteración debidamente individualizada del mundo fenoménico, con la clara determinación de las condiciones de espacio y tiempo en las que se dio la ocurrencia. A la articulación de lenguaje organizada así, con ese carácter de denotatividad, la llamaremos hecho, hecho político, económico, contable, biológico, psicológico, histórico, jurídico, etc. En el derecho positivo, corresponden al antecedente de las normas individuales y concretas. Es aquí donde se encuentra la gran divergencia interpretativa actual. ¿Será que este hecho que da causa a una relación jurídica podrá ser objeto de otras calificaciones no jurídicas? En otras palabras, ¿el hecho antecedente de la norma en el derecho positivo podrá ser entendido como hecho económico, hecho contable, hecho político o incluso hecho histórico? Es lo que vamos a discutir.

Antes, sin embargo, llamo la atención sobre la premisa de que el estatus de los hechos es diferente al estatus de los objetos a que se refieren. El evento, en la visión ontológica, en el sentido de realidad social concreta, para revestir el carácter jurídico precisa ser transcrito en lenguaje competente, es decir, en el

2 CHALHUB, Samira, Funções da Linguagem, São Paulo, Ática, 1991. 
lenguaje jurídicamente admitido como capaz para constituir el antecedente normativo y establecer el vínculo relacional entre agentes del derecho en el plano concreto e individual. Asimismo, no es cualquier función pragmática del lenguaje que propicia la composición de un enunciado factual. Además del lenguaje descriptivo, indicativo o declarativo, muy usado en la comunicación diaria y en el discurso científico, se hace posible emitir enunciados fácticos también en lenguaje prescriptivo y en lenguaje operativo o performativo. Obviamente que los valores lógicos de tales enunciados serán los inherentes al uso empleado: verdadero y falso para el descriptivo; válido e inválido para el prescriptivo; y eficaz e ineficaz para el performativo. A pesar de la función, sin embargo, en todos ellos habrá, necesariamente, un quantum de referencialidad, puesto que son formaciones lingüísticas vertidas al mundo fenoménico de las cosas, y se proyectan en el dominio de los objetos de la experiencia. En la composición de tales enunciados sobre las reglas que orientan la buena formación sintáctica, han de observarse los usos idiomáticos, sin lo que el sentido de aquellas estructuras no será apto para fines denotativos. Y esos fines reclaman la identificación de las ocurrencias en un intervalo de tiempo y en el punto del espacio, dentro de la connotatividad de una hipótesis autorizadora de la construcción del hecho jurídico. Serán, por lo tanto, necesariamente, determinativos. Por ello, el verbo ha de estar en el presente o en el pasado, excluyéndose el futuro.

\section{DISCIPLINARIEDAD Y AUTONOMÍA DEL DERECHO}

La elección del carácter disciplinario o interdisciplinario como estrategia para la construcción del discurso científico, además de opción insoslayable, sigue siendo tema discutido en los círculos epistemológicos, junto con la propia amplitud de la interrelación de las disciplinas, contenido de otra decisión que debe tomar el científico. Todo para perseguir aquel quantum de objetividad que pretende tener contraparte en la carga mínima de subjetividad en el agente del conocimiento.
Se tiene por cierto, en la actualidad, que el conocimiento científico del fenómeno social, sea el que sea, deriva de la experiencia y aparece siempre como una síntesis necesariamente $a$ posteriori. El hecho social, en su congénita e inagotable plurilateralidad de aspectos, reivindica, como objeto, una secuencia de incisiones que le modelan el formato para la adecuada aprehensión del espíritu humano. Está presente en esta actividad tanto la objetivación del sujeto como la subjetivación del objeto, en plena relación dialéctica.

Sin disciplinas, está claro, no tendremos las interdisciplinas, pero el propio saber disciplinario, en función del principio de la intertextualidad, avanza en la dirección de otros sectores de conocimiento, buscando la indispensable complementariedad. La paradoja es inevitable: lo disciplinario lleva a lo interdisciplinario y este último hace volver al primero. La relación de implicación y polaridad, tan presente en el pensamiento de Miguel Reale, se manifiesta también aquí, dado que el perfil metódico que vaya a adoptarse, será, ciertamente, para demarcar una porción de la cultura.

Otros dos obstáculos, en la forma de desafíos, estarán en el camino del estudioso, aunque se admita superada aquella situación paradójica: (i) ¿cuáles son las proporciones del corte? y (ii) ¿qué criterios utilizar para conducir raciocinio en el trato con el objeto ya constituido (digamos, recortado)?

Lo que podemos esperar de quien emprenda la aventura del conocimiento, en el campo de lo social, a esta altura, es una actitud de reflexión, de prudencia, al respecto de las intrínsecas limitaciones y de la propia finitud del ser humano. Esta toma de conciencia, no obstante, no puede representar la renuncia a seguir adelante, expresada en las decisiones que le parezcan más sostenibles para su proyecto descriptivo.

\section{INTERPRETACIÓN DE LOS HECHOS: DELI- MITACIÓN DEL CONTENIDO DE "HECHO PURO", "HECHO CONTABLE" $Y$ “HECHO JURÍDICO"}


Volvamos de la digresión para considerar que, en el nivel de la hermenéutica jurídica, el gran desafío de quien pretenda desvelar el contenido, sentido y alcance de las reglas de derecho radica en la ineluctable dicotomía entre la letra de la ley y la naturaleza del fenómeno jurídico subyacente.

El desprestigio de la llamada interpretación literal es algo que dispensa meditaciones más profundas y basta recordar que, si prevaleciera como método de interpretación del derecho, forzosamente deberíamos admitir que los meramente alfabetizados, quien sabe con la ayuda de un diccionario de tecnología jurídica, estarían acreditados para identificar la sustancia de los mensajes legislados y explicitar las proporciones de significado de la ley. El reconocimiento de tal posibilidad sustraería de la Hermenéutica Jurídica y de la Ciencia del Derecho todo el contenido de sus conquistas; y relegaría la enseñanza universitaria a un esfuerzo sin expresión ni sentido práctico de existencia. Tal vez por ello, y sin percibirlo, Carlos Maximiliano haya secundado, con suficiente énfasis, que todos los métodos interpretativos son válidos, siempre que sus resultados coincidan con aquellos tomados en la interpretación sistemática.

No está demás repetir que, para nosotros, las normas jurídicas son las significaciones que la lectura del texto despierta en nuestro espíritu y que, no siempre coinciden con los artículos en los que el legislador distribuye la materia en el campo escrito de la ley. Dicho de otro modo, en la realidad social en que vivimos, experimentamos sensaciones visuales, auditivas, táctiles, que suscitan nociones. Estas, agrupadas en nuestro intelecto, hacen surgir los juicios o pensamientos que, a su vez, se expresan verbalmente como proposiciones. La proposición aparece como el enunciado de un juicio, de la misma manera que el término expresa una idea o noción. Y la norma jurídica es, exactamente, el juicio hipotético que la percepción del texto provoca en el plano de nuestro consciente, de la misma forma en la que tantas otras nociones no jurídicas podrían haberse originado de aquel mismo conjunto de percepciones físicas. Se dice, por tanto, que la noción es jurídica, pues se enmarcó en una determinada hipótesis jurídica.

Por analogía a símbolos lingüísticos cualesquiera es válida la construcción según la cual el texto escrito es para la norma jurídica como el vocablo lo es para su significación. Y al adoptar la estructura trilateral, de inspiración husserliana, hablaremos de soporte físico, significado y significación. Transportadas las ideas al dominio de lo jurídico: el soporte físico es el conjunto de los textos del derecho législado; el significado, la conducta humana compartida en la vida social; y la significación, el vasto repertorio que el jurista extrae, componiendo juicios lógicos, a partir del contacto sensorial con el soporte físico, y con referencia al marco de los hechos $y$ de las conductas jurídicamente relevantes. Es exactamente en la significación y en el significado que se da la construcción hermenéutica del hecho jurídico y donde centralizaremos todas nuestras atenciones a fin de componer un estudio semántico sobre la expresión "hecho jurídico".

Esto quiere decir, por otros derroteros, que la única forma de entender el fenómeno jurídico, en conclusión, es analizándolo como un sistema, visualizado en el entrelazado vertical y horizontal de los innumerables preceptos, que se congregan y aglutinan para regular el comportamiento del ser humano, en la convivencia con sus semejantes. El texto escrito, en la sencilla expresión de sus símbolos, no puede ser más que la puerta de entrada al proceso de aprehensión de la voluntad de la ley, que jamás se confunde con la intención del legislador. Sin darnos cuenta, nos adentramos en el análisis del sistema normativo desde un enfoque semioticista, que recorta, como todo análisis más serio pide, la realidad jurídica en sus diferentes campos cognoscitivos: sintáctico, semántico y pragmático.

Se sabe que no se puede priorizar ninguna de las dimensiones semióticas, en detrimento de las demás. Sin embargo, el momento semántico, en un análisis más apurado sobre el tema ahora tratado, llama la atención por el modo intenso como califica y determina las cuestiones someti-

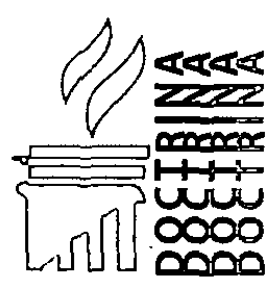


das al proceso dialógico que prepara la decisión o conclusión. De ahí la exclamación de Alfredo Augusto Becker, repleta de fuerza retórica, según la cual el jurista no sería más que el semántico dellenguaje del derecho. A él le corresponde la ardua tarea de examinar los textos, tantas veces oscuros, contradictorios, penetrados de errores e imperfecciones terminológicas, para captar la esencia de las instituciones, obteniendo, con nitidez, la función de la regla, en el complicado marco normativo.

En el proceso de cognición del lenguaje prescriptivo de conductas, el hermeneuta tropieza con numerosas trabas que la propia realidad jurídica le impone. El primer obstáculo está enclavado en la propia matriz del derecho. La producción de las normas de más elevada jerarquía en el sistema, que son generales y abstractas, se confía a los parlamentos, casas legislativas de natural heterogeneidad, en la medida en que se pretendan democráticas y representativas. Con ello, a pesar de los esfuerzos en la elaboración de un lenguaje técnico, dotado de racionalidad suficiente para alcanzar parámetros satisfactorios de eficacia social, lo cierto es que el mensaje legislado casi siempre viene penetrado de imperfecciones, con problemas de orden sintáctico y semántico, lo que hace que muchas veces sea difícil su comprensión por parte de los sujetos destinatarios. Es en este punto que la Dogmática (Ciencia del Derecho en sentido estricto) cumple un papel de extrema relevancia, al componer los enunciados que con frecuencia se hallan dispersos en distintos cuerpos legislativos, los acomoda en la estructura lógica compatible y apunta las correcciones semánticas que la lectura contextual sugiera. Con tales ponderaciones, la comunicación normativa fluye con más facilidad del emisor al receptor, para realizar los propósitos de la regulación jurídica con mayor clareza y determinación.

En un segundo momento, el estudioso se depara con una realidad jurídicamente compleja. Analizando, en el contexto de una visión sistemática, donde las unidades normativas se interconectan para formar una estructura sintáctica; donde, inequivocamente, hay un referente semántico consubstanciado por la zona material de la conducta, punto de confluencia de las iniciativas reguladoras del comportamiento intersubjetivo; y donde se verifican las inagotables manifestaciones de los factores pragmáticos, todo ello, repito, trae al estudio del fenómeno jurídico complejidades inmensas. En calidad de exegeta, debe partir de la literalidad del texto y buscar las significaciones sistémicas, aquéllas que retratan los propios parámetros instituidos por el sistema. Del mismo modo, la consistencia material de las reglas tiene que encontrar fundamento en el sistema, so la pena de que no prevalezcan y sean desconstituidas. De ahí la tendencia de cortar de raiz el problema ofertando soluciones simplistas y no comprometidas, como ocurre, por ejemplo, con la intrincada "interpretación literal" de las formulaciones normativas, que lleva consigo la dulce ilusión de que las reglas del derecho pueden ser aisladas del sistema y analizadas en su compostura de frase, por tanto, "comprendidas".

Si se adopta tal postura, nos parece perfectamente justificada y coherente la adopción de la afirmación antes colocada de que las reglas jurídicas son las significaciones que la lectura del texto despierta en nuestro espiritu $y$, ni siempre, coinciden con las disposiciones mediante las cuales el legislador distribuye la materia en el cuerpo escrito de la ley. Deriva de aqui que, muchas veces, un único artículo no sea bastante para comprender la norma, en su integridad existencial. Se ve el lector, entonces, en la contingencia de consultar otros preceptos del mismo título e, incluso, de salir de él para hacer incursiones por el sistema.

Por último, no nos olvidemos de que la capa lingüística del derecho está inmersa en la complejidad del tejido social, cortada solo a efectos de aproximación cognoscitiva. Lo real, con la multiplicidad de sus determinaciones, solo es susceptible de una representación intuitiva, aunque sometida a innumerables recortes cognoscitivos. Con tales ponderaciones, se hace hialina la afirmativa de que de un mismo evento el jurista podrá construir el hecho jurídico, como también el contable, y el economista el hecho económico. Todo, por tanto, depende del corte que se quiera hacer de ese evento. 
Y en cuanto al ámbito de comprensión de este fenómeno, volviendo sobre la línea de raciocinio inicial, citemos que todos los hechos son construcciones de lenguaje $y$, por ello, son representaciones metafóricas del propio evento. Siguen la gramaticalidad propia del universo lingüístico al que pertenece -el jurídico- cuando es constituyente del hecho jurídico, o el contable, por ejemplo, cuando son constructores del hecho contable. Las reglas de la gramática cumplen una función lingüística reguladora de un idioma históricamente determinado. Prescriben la forma de combinación de los vocablos y de las expresiones para que produzcamos una oración, esto es, una construcción con sentido de aquel universo lingüísticamente dado. El Derecho, por tanto, es lenguaje propio compositivo de una realidad jurídica. De aquí resulta el que se denomine Gramática Jurídica al subconjunto de las reglas que establecen cómo otras reglas deben establecerse, modificarse o extinguirse, dentro de cierto sistema.

Una vez señalado esto, percibiremos que la construcción del hecho jurídico no es más que la constitución de un fraseado normativo capaz de yuxtaponerse como antecedente normativo de una norma individual y concreta, dentro de las reglas sintácticas impuestas por la gramática del derecho, así como de acuerdo con los límites semánticos proyectados por la hipótesis de la norma general y abstracta.

Se debe tener en mente, en este camino, una importante información: las palabras que componen esta frase constitutiva de realidad jurídica tienen una denotación, que es el conjunto de los significados que, posteriormente, representan el signo. Al mismo tiempo, las palabras clasifican dicotómicamente, en la medida en que establecen dos categorías, respectivamente, la de los objetos que representan y la de los objetos que no representan.

Esto ocurre con la expresión hecho juridico. En la actualidad, se tiene por cierto, que el conocimiento científico del fenómeno social, sea el que sea, deriva de la experiencia y aparece siempre como una síntesis necesariamente, $a$ posteriori. En la constitución del hecho jurídico, el análisis de la relación entre el lenguaje social y el lenguaje jurídico, reductor del primero, se superpone sobre este conocimiento sintético, obteniendo como resultado un nuevo signo, individualizado en el tiempo y en el espacio del derecho y que recibe calificación jurídica: este es el hecho jurídico. Es, por tanto, una construcción de superlenguaje. Hay dos síntesis: (i) del fenómeno social al fenómeno abstracto jurídico y (ii) del fenómeno abstracto jurídico al fenómeno concreto jurídico.

Adoptados estos presupuestos, verificaremos que el término o expresión que adquiera el calificativo "jurídico" no solo será representativo de una unidad del universo del derecho, sino también denotará su contrapunto, que son todos los otros hechos lingüísticamente posibles de ser construidos a partir de aquel mismo evento, pero que no se encuadran en las reglas sintáctica y semánticamente dadas por el sistema de lenguaje del derecho. La demarcación del objeto implica la delimitación del corte de su clase $y$, al trazar estos límites, el exegeta obtiene como resultado indirecto la formación del conjunto de los hechos que no se califican como tal. Se trata de la sencilla construcción resultante de la lógica pues, en el universo de las proposiciones normativas, " $p$ " (proposición) es diferente y opuesto de " $n-p$ " (no proposición), lo que impide a quien se dispone a conocer el sistema incluir la clase " $n-p$ " dentro del conjunto " $p$ ". Son categorías que toman el mismo universo pero que no se entrecruzan. Es decir, de un mismo evento puede construirse un hecho jurídico o un hecho contable; pero uno y otro son sobremanera diferentes, lo que impide colocar el último como antecedente de la norma individual y concreta, dado que representa unidad ausente de significación jurídica. El hecho capaz de implicar el consecuente normativo deberá ser siempre el hecho jurídico, aunque muchas veces haya situaciones en que en uno y otro estén presentes los mismos contenidos denotativos. A partir de estos datos podremos demarcar el conjunto de los hechos jurídicos y separarlo del conjunto de los hechos no jurídicos, donde se sitúan los hechos económicos, los hechos contables, los hechos históricos y tantos otros como sean las ciencias que los construyen.

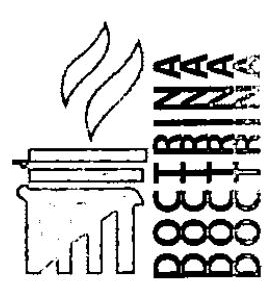

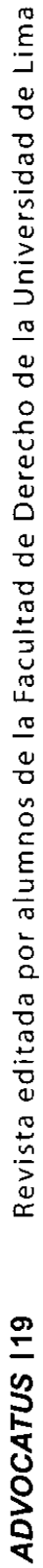


El criterio utilizado para separar estos dos universos es justamente la homogeneidad sintáctica del universo jurídico.

Con tales consideraciones es oportuno recordar que todo conocimiento del objeto requiere cortes y más recortes científicos, que cumplen la función de simplificar la compleja realidad existencial al delimitar el campo de análisis. No olvidemos que la capa lingüística del derecho está inmersa en la complejidad del tejido social, cortada solo al efecto de lograr la aproximación cognoscitiva. El derecho positivo es objeto del mundo de la cultura y, como tal, hace ardua la tarea del exegeta de construir la plenitud de sus contenidos de significación, obligándolo a reducir la complejidad empírica, ora aislando, ora seleccionando caracteres del dínámico mundo del existencial. El hecho social, en su congénita e inagotable plurilateralidad de aspectos, reivindica, en cuanto objeto, una secuencia de incisiones que modelan su formato para la adecuada aprehensión por el espíritu humano. Está presente, en esta actividad, tanto la objetivación del sujeto como la subjetivación del objeto, en plena relación dialéctica. El objeto pasa a ser una construcción en lenguaje del intérprete que reduce las características propias e inmanentes de aquello que toma del universo físico-social.

He aqui una barrera infranqueable a la concepción del "hecho puro", ya sea económico, histórico, político, jurídico o de cualquier otra calidad que se le pretenda atribuir. Tales hechos, como añade Lourival Vilanova, son elaboraciones conceptuales, subproductos de técnicas de depuración de ideas selectivamente ordenadas. ${ }^{3}$ Establezco la premisa según la cual no es posible, por eso mismo, aislar, dentro de lo social, el hecho jurídico, sin una serie de cortes que representen, en una ascesis temporal, el despojo de aquel hecho cultural mayor de sus colores políticos, económicos, éticos, históricos, etc., asi como de los resquicios de la implicación del observador, en el incesante flujo de su estructura emocional.
Es oportuno hacer una observación importante que se dirige al momento de la propia consolidación de la afirmativa antes expuesta. Esto porque la doctrina tradicional está tiñendo ciertos hechos jurídicos, como el hecho elusivo, como construcción de contenido económico, con efectos jurídicos. Así entiende Amílcar de Araújo Falcão, que lo califica como hecho jurídico de contenido económico o incluso hecho económico de relevancia jurídica. Distracciones de este género, conducirán el pensamiento hacia la idea de que es necesario que el derecho tome prestado el hecho económico para cumplir con sus funciones prescriptivas de conducta. El hecho elusivo, en sí, se abstenía de tener naturaleza jurídica. Bien, pasemos a examinar los criterios que componen las mencionadas afirmativas.

Con el deseo de construir un recorte de la realidad que cerque el hecho jurídico elusivo, se deslizan pensamientos a lo largo del eje descriptivo, impulsados por una elocuencia ordenada y vigorosa, en la medida que la ciencia recomienda. A fin de cuentas, ¿qué hecho es aquel? ¿Cómo calificarlo? ¿Con qué criterio? Nunca está demás insistir que las subdivisiones en sistemas responden a cortes metódicos que los objetivos de la indagación analítica imponen al espíritu del investigador. El criterio adoptado en el corte es el que calificará el hecho construido por él, que lo cuantificará, incluso, en su consecuente normativo. Si adoptamos un criterio jurídico, el hecho se considerará ora como jurídico, ora como no jurídico, de acuerdo con las características establecidas en ley que determinan los contornos de ese factum tributario. Si se adopta tal presupuesto, la referencia siempre se contendrá en los criterios legalmente estipulados.

Al indagar sobre la expresión economía fiscal, con una mirada ligera, entenderemos que está en el límite entre lo que es del dominio económico y lo que es del derecho. ¿En cuál de estos universos se insiere el criterio? Cabe observar que, cuando establecemos el paralelismo entre el resultado de dos situaciones fiscales, estare-

3 Confiera: "El hecho puro no lleva, con él, la suficiente relevancia significativa para que se incluya dentro del tipo. Para ingresar, sufre una valoración dirigida por un deber ser". (VILANOVA, Lourival, Estruturas Lógicas e o Sistema de Direito Positivo, p. 104). 
mos ingresando en un análisis aritmético entre dos cuantías o dos resultados numéricos. ¿Sería un análisis jurídico o económico? Veamos. Si se traslada esto al marco de las prescripciones legales tributarias, verificaremos, en el propio artículo 3 del Código Tributario Nacional (CTN), que el tributo es una prestación pecuniaria compulsoria, en moneda o cuyo valor en ella se pueda expresar. En otras palabras, el tributo es un valor pecuniario. Y el propio artículo 4 del CTN, cuando dice que la naturaleza específica del tributo se define por el hecho generador, está confirmando que la naturaleza del tributo la da por la conjugación de la hipótesis de incidencia y de la base de cálculo, que asume, en esta operación, perfil numérico.

De todo lo expuesto, queda la observación de que no hay hechos jurídicos puros o hechos económicos puros. Lo que existe son cortes de lenguaje. Nosotros, juristas, montamos la realidad que representa el corte. De esta manera construimos la interpretación jurídica. Nada de esto impide que economistas tomen la misma base objetiva y produzcan enunciados económicos sobre ella. Se producen, a su vez, otros cortes sobre el mismo acontecimiento, que componen un nuevo signo. Y lo mismo sucede para el historiador, que constituye el hecho histórico; para el sociólogo, que construye el hecho sociológico, entre tantos otros recortes que se puedan producir en esta realidad. A la confusión metodológica que se establece en el instante del corte Becker llamó "mancebía irregular" del Derecho Tributario con otras ciencias. Además, fue precisamente por la pretensión de fijar como objeto la actividad financiera del Estado, pasando a examinarla desde todos los ángulos posibles e imaginarios, sin ninguna prioridad metodológica, que la Ciencia de las Finanzas rotundamente falló y ya no existe como asignatura en los planes académicos de las Facultades de Derecho de Brasil.

Discurriendo sobre el modo de pensar algunas veces irreflexivo de la doctrina tradicional, tam- bién conocida como doctrina del «buen actuar» del Derecho Tributario, Alfredo Augusto aclara: "Ejemplo de falta de actitud mental jurídica es la divulgadisima tesis (aceptada como cosa obvia) que afirma que la hipótesis de incidencia ("hecho generador", "hecho imponible", "soporte fáctico") es siempre un hecho económico. Otro ejemplo actual es la muy propagada doctrina de la interpretación y aplicación del Derecho Tributario según la "realidad económica del fenómeno social". Como se demostrará, ambas teorías tienen como resultado la demolición de la juridicidad del Derecho Tributario y la gestación de un ser hibrido y teratológico: el Derecho Tributario invertebrado". (subrayado del autor).

\section{LA CONCEPCIÓN DEL DERECHO COMO SISTEMA AUTOPOIÉTICO}

Para la teoría de los sistemas, en el modelo Luhmanniano, el derecho constituye un sistema autopoiético de segundo grado, que ha adquirido autonomía frente al sistema autopoiético general, que es la sociedad. Surgen los ordenamientos jurídicos como subsistemas autónomos por el surgimiento de un código propio y diferenciado (lícito/ilicito), preparado para dar estabilidad a un proceso equilibrado de autoproducción recursiva, cerrada y circular de comunicaciones exclusivamente juridicas. Celso Campilongos ${ }^{5}$ en un dilucidador texto, aclara la proposición de Luhmann, mediante la cual el derecho promueve la generalización congruente de las expectativas normativas. El iusfilósofo paulista examina, palabra por palabra, las proporciones semánticas de aquel mensaje, dejando bien clara la manifestación del pensador alemán.

El repertorio de este sistema está formado por actos de comunicación (que presuponen necesariamente el lenguaje), articulados reiteradamente, que se autorreproducen a la luz de aquel código binario (lícito/ilícito), que construyen su medio envolvente propio (realidad jurídica) y demarcan los límites del territorio del derecho.

4 BECKER, Alfredo Augusto, Teoria Geral do Direito Tributário, 4a, edição,Marcial Pons/Noeses.

5 CAMPILONGO, Celso, Política, Sistema Jurídico e Decisão Judicial, Max Limonad, São Paulo, 2002, p.19. 
Este subsistema se caracteriza por ser normativamente cerrado, aunque cognitivamente abierto, es decir, opera mediante métodos que le son exclusivos, pero intercambia informaciones con otros subsistemas, al emitir actos comunicativos (normas) y, al mismo tiempo, recibir de otros subdominios las noticias por ellos producidas. Dando importancia a su autonomía, como subsistema, el derecho procesa sólo las informaciones que le interesan y las somete, entonces, a los criterios metodológicos de formación de normas. De ahi la conclusión de Marcelo Neves": "La positivación del Derecho en la sociedad moderna implica el control del código-diferencia "licito/ilicito" exclusivamente por el sistema juridico, que adquiere de esa manera su clausura operativa". Y sobre la fuerza e intensidad de la mencionada autonomía, es oportuno consignar la posición categórica de Gunther Teubner?:"Las comunicaciones juridicas construyen la "realidad juridica" en el llamado tipo o hipótesis legal de una norma jurídica. Los elementos típicos ofactispecies normativos incorporan distinciones intrínsecamente juridicas, que permiten asi al sistema juridico producir sus propias categorizaciones. De este modo, en los actos legislativos, el derecho como que inventa su propio medio envolvente". Y, más adelante: "Quiere decir: desde un punto de vista constructivista, las intervenciones del derecho en la economia deben entenderse como observaciones reciprocas entre dos sistemas de comunicación herméticamente cerrados y autónomos. El derecho "inventa" una imagen de la economia y formula las respectivas normas con referencia a dicha imagen. La economía "inventa" una imagen del derecho y procesa los actos de pago también con referencia a ésta. $Y$ aunqueestos modelos imaginarios intrasistémicos del mundo exterior puedan refinarse de manera continua, como ocurre con la moderna escuela del análisis económico del derecho, la verdad es que esto jamás los conducirá de las concepciones jurídicas del sistema económico a la realidad del propio sistema económico. ${ }^{8}$

Véase como se refuerza la tesis de la autonomía del derecho, cuando trata la Teoría de los Sistemas.

\section{LA IMPOSIBILIDAD DE TRADUCCIONES PERFECTAS ENTRE LOS IDIOMAS DE LA MISMA FAMILIA Y EL DIÁLOGO QUE ENTRE ELLOS SE ESTABLECE SEGÚN LA CONCEPCIÓN DE VILÉM FLUSSER}

En su Lingua e Realidade, Flusser contribuye de forma valiosa al estudio de la traducción entre idiomas. Además de establecer proposiciones sugestivas sobre que la lengua es la realidad, forma la realidad y crea la realidad, menciona el diálogo que se establece entre tales órdenes para formar las distintas culturas, el pensador checo proclama, con bastante claridad, que las ciencias son lenguas, de modo que las observaciones aplicables a los sistemas idiomáticos se acomodan perfectamente al esquema organizativo de las ciencias. Escuchémosle. "La ciencia sensu stricto, tal como la conocemos en Occidente, desde el Renacimiento, equivale, desde este punto de vista, al surgimiento de una nueva lengua".' Y Gustavo Bernardo Krause, en el prefacio de esta obra prima, como él mismo reconoce, reproduce el texto de Flusser: "La ciencia, lejos de ser válida para todas las lenguas, es la propia de una lengua que se traduce a las demás".10

Vilém Flusser, de hecho, no admite la posibilidad de traducción perfecta, aunque se trate de lenguas flexionales, con una organización parecida. Solo es posible de forma aproximada, gracias a las semejanzas existentes entre las estructuras de los idiomas. De ahí el adagio consagrado: traduttore, traditore. Entre las realidades crea-

6 NEVES, Marcelo, A Constitucionalizaçāo Simbólica, Editora Acadêmica, Sāo Paulo, 1994, os. 119/120.

7 TEUBNER, Gunther, O Direito como sistema autopoiético, Fundação Calouste Gulbenkian, Lisboa, p.157.

8 Ídem, p. 160.

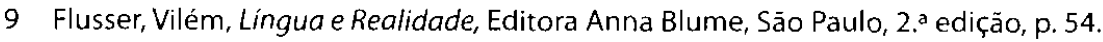

10 Ídem, p. 19. 
das y formadas por dos lenguas diferentes, aunque semejantes, hay un abismo que tiene que transponerse, momento en el que surgen las inevitables distorsiones.

Ahora bien, si el Derecho (tomado aquí como ciencia) y la Economía, son dos sistemas cognoscentes distintos, entre ellos solamente podrá haber una traducción aproximada, con la presencia de términos y expresiones intraducibles que determinan frecuentes descompases. Sin embargo, pueden mantener un amplio diálogo, que envuelva también el saber al respecto de otros segmentos del tejido social, como la Ciencia Política, la Sociología (en sentido estricto), las Ciencias Contables, la Psicología Social, la Historia, etc.

\section{CONCLUSIÓN}

Con apoyo en los argumentos que acabo de exponer, en forma de premisas, es intuitivo concluir que los hechos, así como toda construcción de lenguaje, pueden ser observados como jurídicos, económicos, antropológicos, históricos, políticos, contables, etc.; todo dependiendo del criterio adoptado por el corte me- todológico emprendido. ¿Existe interpretación económica del hecho? Sí, para los economistas. ¿Existirá interpretación contable del hecho? Ciertamente, para el contable. No obstante, una vez asumido el carácter jurídico, el hecho será, única y exclusivamente, hecho jurídico; y claro, hecho de naturaleza jurídica, no económica o contable, entre otras materias. Como ya se ha anotado, el derecho no pide prestados conceptos de hechos a otras disciplinas. Él mismo construye su realidad, su objeto, sus categorías y unidades de significación. La paradoja inevitable, y que causa perplejidad en el trabajo hermenéutico, justifica la circunstancia de que el disciplinario lleve al interdisciplinario y que este último haga volver al primero. Sin disciplinas, por tanto, no tendremos las interdisciplinas, pero el saber disciplinario mismo, en función del principio de la intertextualidad, avanza en la dirección de los otros sectores del conocimiento, buscando la indispensable complementariedad. Tanto el jurídico como el económico forman parte del dominio social y, por tener este referente común, se justifica que entre uno y otro haya aspectos o áreas que se entrecrucen, pudiendo dar lugar a una traducción aproximada y, en parámetros más amplios, un denso y provechoso diálogo.

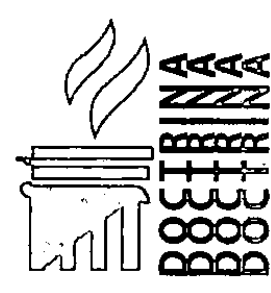

